\title{
Athletic Development Personality Relationship Emphasis on Global Business Leadership Challenges in Today's Environment
}

\author{
Herbert J. DeGraffe, Jr., Ph.D. \\ Walden University \\ United Management Consortium
}

\begin{abstract}
Researchers have indicated that executive coaching can help senior executives identify leadership failures due to personality factors defects by exposing these attributes of effective executive decision-making in the organization. Thus, proving the bright side of personality versus the dark side of the personality has various dimensions based on failed companies' experiences, cultural aspects, cognitive and executive skill transfer, and the longitudinal nature of leadership development. The participants included 124 executive decision-makers from the United States, the United Kingdom, South Africa, India, and Singapore completing an online survey. Resulting in 3 variable models being significant; focus, ethicalness, and leadership. Found decision making scores to be higher for respondents significantly contributed to the model.
\end{abstract}

\section{INTRODUCTION}

$\mathrm{R}$ esearchers are presenting challenges that people cannot ignore or avoid due to leaders and followers' perceptions and interpretation of the world. This view is problematic in dramatic changes in the occurrences in a complex reality that has no protection. Therefore, it is necessary to address, evaluate, and understand global leadership decision-making and threats and uncertainties on the world stage (Endrijaitis \& Alonderis, 2015). Past and current organizational leaders have shown that leadership alignment in the business, organizational, and political environment is a problem in the United States. Researchers have and are conducting quantitative research to show the decision-making challenges executive leadership faces. This business focuses on the quantitative and theoretical frameworks that enhance the interpretation and analysis phases for understanding global leadership alignment. A change in an interactionist framework reflects the characteristics of organizational contexts under a particular trait, ability, or motivational orientation that will predict behavior and performance (Farh, Seo, \& Tesluk, 2012). Business alignment helps decision makers through a successful or failed implementation of the applied strategy of an initiative.

The purpose of the study was to determine whether the informed athletic development personality factors collaboration, focus, trustworthiness, ethicalness, and leadership correlate with the decision-making of individuals in leadership positions. This interpretation of the findings and the discussion of the study's limitations was an extensive review of the recommendations for future research, positive social change ramifications, and a discussion of its implications. Thus, the discussions included various operationalization of all the variables and background information on the reliability of the survey instruments, which encompassed directors, managers, and decision makers in the five countries: the United States, the United Kingdom, South Africa, India, and Singapore, with 124 respondents lived in one of five English-speaking countries. The study included one research question: What is the relationship between athletic development personality factors and decision making at the executive leadership level of an organization, along with two hypotheses.

$H_{0}$ : There is no significant relationship between decision making for executive leadership and athletic development personality factors.

$H_{a}$ : There is at least one significant athletic development personality factor related to decision making at the executive leadership level.

$Y_{i}=\beta_{0}+\beta_{1} X_{1 i}+\beta_{2} X_{2 i}+\beta_{3} X_{3 i}+\beta_{4} X_{4 i}+\beta_{5} X_{5 i+} \epsilon_{i}$,

$H_{0}: \beta_{1}=\beta_{2}=\beta_{3}=\beta_{4}=\beta_{5}=0$

$H_{a}$ : At least one $\beta_{i} \neq 0$,

\section{Problems in Management}

Researchers have indicated that ineffective or destructive leadership is a concern and that between $33 \%$ and $61 \%$ of leaders act destructively (Gaddis \& Foster, 2015). The general problem is that executive leadership failures occur because of defects in athletic development personality factors, core executive functions, and emotional decision-making (Antes et al., 2012; Gaddis \& Foster, 2015; Ross et al., 2014). The specific problem was identifying whether or not there were any defects among athletic development personality factors in the correlational relationships to executive leadership decision making (see Gaddis \& Foster, 2015; Holten et al., 2015; Towndrow \& Vallance, 2013). 
Table 1: Psychometric Characteristics for the Aggregated Scale Scores

\begin{tabular}{|l|c|l|l|l|l|l|}
\hline Scale & No. of items & $M$ & $S D$ & Low & High & $\alpha$ \\
\hline Collaboration & 7 & 5.67 & 0.67 & 3.71 & 6.86 & .73 \\
\hline Focus & 6 & 5.87 & 0.65 & 4.17 & 7.00 & .74 \\
\hline Trustworthiness & 9 & 5.38 & 0.72 & 4.00 & 7.00 & .74 \\
\hline Ethicalness & 5 & 6.00 & 0.62 & 4.20 & 7.00 & .80 \\
\hline Leadership & 7 & 5.71 & 0.70 & 4.14 & 7.00 & .77 \\
\hline Decision Making & 10 & 5.91 & 0.59 & 4.40 & 7.00 & .88 \\
\hline
\end{tabular}

Note. Scales based on a 7-point scale: $1=$ strongly disagree to $7=$ strongly agree.

\section{LITERATURE REVIEW}

Personality factors are elements of the psychological health of an individual, and sport is an inhibitor to a person's mentalization for psychological health. Researchers have analyzed the personality traits of people participating in sport recreationally and at a competitive level to understand sports demand. Identifying personality traits is essential to team performance to determine the characteristics of particular interest, such as collaboration, focus, trustworthiness, ethicalness, leadership, and decision-making (Young et al., 2013). The need for these athletic development personality resources will provide the personal skills for motivating individuals for positive collective performance (Young et al., 2013). Executive leaders in NASCAR motorsports advocate that racing needs able leaders who can hold individuals accountable to provide a common focus for their organizations in the assigned tasks to do what they say with a commitment to openness and honesty.

Cattell's 16-personality factor model is the core path to the principles that established the five-factor model of personality. Cavallera, Passerini, and Pepe (2013) used Cattell's 16 personality factors to observe that swimmers were more assertive, enthusiastic, conscientious, apprehensive, selfsufficient, reserved, and socially precise from other physical movements such as tennis and golf. Male athletes lean toward being more active, aggressive, competitive, dominating, and controlling, in contrast to female athletes who become more goal oriented, organized, and rule-governed (Cavallera et al., 2013). The language of the categorical adjectives ended up with a factor analysis of 35 clusters that created a hierarchy of 16 personality traits.

There are grammatical variances among trait adjectives, such as athletic and athlete, which is a stereotype noun. The practice of using social categories rather than traits needs further research regarding the increased activation of the mentalizing network that allows distinction between the visualization task and behavioral processing (Van der Cruyssen et al., 2015). The characteristics of resilience, confidence, commitment, self-belief, concentration and the ability to cope with pressure represent mental toughness (Delaney, Goldman, King, \& Nelson-Gray, 2015). A review of the different tasks presented revealed concerns about the differential impact of social categories and traits that limit the methodological limitations in interpreting the result.

\section{METHODOLOGY}

The study scale items consisted of six traits (collaboration, focus, trustworthiness, ethicalness, leadership, and decisionmaking) selected from the well-known IPIP, an online public domain repository of empirically tested scales. For instance, survey items may measure an individual's passion for the motorsports industry's independent variables relationship (Young et al., 2013). The validity of measurement affects the validity of a conclusion after hypothesis testing is complete (Table 4). Measuring variables in this study did not involve using the well-established five-factor model of personality traits survey instrument, which might have been too general for this study. The motorsport-selected scales were appropriate for the context based on success factors identified from Young et al.'s (2013) study.

\section{RESULTS}

This interpretation of the study's findings indicated whether the data supported or did not support the null hypothesis ( $\mathrm{H} 0$ : $\mathrm{B} 1=\mathrm{B} 2=\mathrm{B} 3=\mathrm{B} 4=\mathrm{B} 5=0)$, which showed no significant relationship between decision making for executive leadership and athletic development personality factors. Data analysis showed that significant positive correlations existed between collaboration and decision making, $r=.60, p<.60$, which had a strong correlation; focus and decision making, $r=.749, p<.741$, which had a strong correlation; and ethicalness and decision making, $r=.662, p$ $<.662$, which had a strong correlation, with leadership and decision making, $r=.67, p<.67$ showing a strong correlation as well. The significant positive correlation between trustworthiness and decision-making showed a moderate correlation at $r=.569, p<.569$ (see Table 2).

Table 2 Pearson Intercorrelations Among the Scale Scores

\begin{tabular}{|c|c|c|c|c|c|c|}
\hline Scale score & 1 & 2 & 3 & 4 & 5 & 6 \\
\hline $\begin{array}{l}1 . \\
\text { making }\end{array}$ & 1.00 & & & & & \\
\hline 2. Collaboration & .60 & 1.00 & & & & \\
\hline 3. Focus & .75 & .63 & 1.00 & & & \\
\hline $\begin{array}{l}4 . \\
\text { Trustworthiness }\end{array}$ & .57 & .68 & .59 & 1.00 & & \\
\hline 5. Ethicalness & .66 & .45 & .61 & .43 & 1.00 & \\
\hline 6. Leadership & .67 & .71 & .71 & .64 & .57 & 1.00 \\
\hline
\end{tabular}

Note. $\mathrm{N}=124$. All correlations were significant at the $\mathrm{p}<.001$ level.

Based on the findings, the alternative hypothesis $H_{a}$ was accepted; there was at least one $\beta_{i} \neq 0$. At least one significant athletic development personality factor related to decision making at the executive leadership level. The Pearson correlation displayed the effect size and correlation strength for the absolute value of r (see Evans 1996). Data analysis indicated that the five athletic development personality factors, collaboration, focus, trustworthiness, ethicalness, and 
leadership, correlate with decision making, but the correlation varies from very weak to very strong.

\section{DISCUSSION}

The five athletic development personality factors identified in Young et al.'s (2013) research were used as a reliability scale comparison in the measurement (see Table 4). Consequently, answering the research question helped determine if significant correlations existed between athletic development personality factors and decision-making. Therefore, developing successful interpersonal relationships can contribute to an individual's ability to inspire others by teaching a future vision. For this reason, the subdimensions of leadership ability can fit into four skillset groups: confidence, autonomy, people-oriented, and task-oriented (Chien, 2014). Therefore, categorized leadership abilities are a continuum of personality factors expressed by describing a relationship in the social interactions between individuals within and outside an organization.

Many researchers regard social exchange as a sequence of giving and taking to create a mutual obligation between two parties and, in essence, showing that exchanges are usually two-way and dependent on both sides' behavior (Naseer et al., 2016). Consequently, the relationships showed that all five athletic development factors correlated with decision making; the regression approach eliminates redundant predictors from a model and protects against multicollinearity (Field, 2013). In contrast, the resulting three-variable model was significant: $Y_{\mathrm{i}}=0.99+0.40$ (Focus) +0.27 (Ethicalness) +0.17 (Leadership) ${ }_{+} \epsilon_{\mathrm{i}}$ and according to these findings, collaboration and trustworthiness were nonsignificant athletic development personality factors. For instance, the sample sizes of the Spearman correlations were similar to those statistical measurements based on the original Pearson correlations (see Table 2). Again, the correlations were weak, which showed variance between the five countries. In addition, these personality factors were not significant in correlation in all. However, one out of six test scores personality factor in Oneway ANOVA tests with none eta coefficients $(\eta)$ were of moderate strength according to (Cohen's (1988). Nevertheless, each of these results was from the country, age group, and gender, respectively.

The model for the standard multiple regression was significant $(p=.001)$ and accounted for $65.7 \%$ of the variance in the dependent variable. It was subsequently using standard multiple regression equations for the decision making based on the five personality factors. Again, using the stepwise regression model to eliminate redundant predictors from the model and protect against multicollinearity (Field, 2013). These findings provided support for the alternate hypothesis (see Tables 2 and 3), with the results of the Pearson intercorrelations showing that all five personality factors had significant positive correlations with the decision-making score. Therefore, the data did not support the null hypothesis (see Field, 2013). Although, all five correlations were at least $r=.57$, with the largest correlation between the focus personality factor and decision-making, $r=.75, p<.001$.

The alternative hypothesis that personality factors correlated with decision making received support (see Tables 1). In the interpretation of the $R^{2}$ is the variance accounted for in the dependent variable (percentage of the reasoning) in Model 1 (full model), $F(5,118)=45.22, p=.001, R^{2}=.657$, and Durbin-Watson $=2.29$. The sum of $R^{2}=.657$ is the coefficient of determination for multiple regression (see Table 3 ). The $R^{2}$ is the variance accounted for in the dependent variable (percentage of reasoning). The correlation could not be explained or accounted for in the variability of its mean response data of its mean was .343. This variable response is the data that a researcher cannot explain but can account for in new research.

Table 3 Prediction of Decision Making Based on the Five Personality Factors Using Standard Multiple Regression

\begin{tabular}{|l|l|l|l|l|l|l|}
\hline Variable & $B$ & $S E$ & $\beta$ & $p$ & $\begin{array}{l}\text { Toleran } \\
\text { ce }\end{array}$ & $\begin{array}{l}\text { Variance } \\
\text { inflation } \\
\text { factor }\end{array}$ \\
\hline Intercept & 0.83 & 0.35 & & .020 & & \\
\hline Collaboration & 0.08 & 0.08 & .09 & .320 & 0.39 & 2.54 \\
\hline Focus & 0.35 & 0.08 & .39 & .001 & 0.40 & 2.49 \\
\hline $\begin{array}{l}\text { Trustworthin } \\
\text { ess }\end{array}$ & 0.07 & 0.06 & .09 & .270 & 0.47 & 2.11 \\
\hline Ethicalness & 0.27 & 0.07 & .28 & .001 & 0.59 & 1.71 \\
\hline Leadership & 0.10 & 0.08 & .12 & .190 & 0.35 & 2.87 \\
\hline
\end{tabular}

Note. $\mathrm{N}=124$. Full model: $\mathrm{F}(5,118)=45.22, \mathrm{p}=.001 . \mathrm{R}^{2}=.657$. DurbinWatson $=2.29$.

Among the country subsamples, the country-specific correlations for most countries were similar in size to those found in the entire sample. However, in the South Africa subsample, the correlations were smaller, with two of the five correlations not significant at the $p<.05$ level (see Table 6). In addition, the Indian sample correlation was more significant between decision-making and the five personality factors than they were for the entire sample (see Tables 18, 19, and 20). The Spearman correlations found that all items had significant positive correlations with the age and gender category decision-making scale. Indicated the individual collaboration items with the decision-making scale having the most significant correlations.

When examining the strength of the relationship between two variables that did not rely on a parametric test's assumptions, it considers the individual items. Thus the highest levels of agreement and the lowest level of agreement, the mean scores were converted into ranked scores from the Pearson's correlation coefficient performed on the data. The intraclass correlation coefficient is used to assess the consistency between measures of the same class and the relationship between variables of a different class (Field, 2013). Similarly, the items of each personality factor were used to assess the consistency between the individual mean 
raters score $N=124$ for the calculation of the correlations to see if there was a measure of uniformity (see Table 4).

Table 4 Scale Items and Reliabilities for Constructs

\begin{tabular}{|c|c|}
\hline Construct & $\begin{array}{l}\text { Reliability } \\
\text { Score }\end{array}$ \\
\hline Collaboration & 0.732 \\
\hline \multicolumn{2}{|l|}{$\begin{array}{l}\text { 6. I support fellow group members when working as a leader } \\
\text { of a team. (agree) }\end{array}$} \\
\hline \multicolumn{2}{|l|}{$\begin{array}{l}\text { 14. I work cooperatively with employees when working as a } \\
\text { leader of a team. (agree) }\end{array}$} \\
\hline \multicolumn{2}{|l|}{$\begin{array}{l}\text { 18. Participating in an individual sport in college exposes } \\
\text { the lack of a teamwork culture. (disagree) }\end{array}$} \\
\hline \multicolumn{2}{|l|}{$\begin{array}{l}\text { 20. I am sensitive to the needs of employees when working } \\
\text { as a leader of a team. (agree) }\end{array}$} \\
\hline \multicolumn{2}{|l|}{$\begin{array}{l}\text { 32. Participating in a team sport in college is a beneficial } \\
\text { experience in working with employees. (agree) }\end{array}$} \\
\hline \multicolumn{2}{|l|}{$\begin{array}{l}\text { 34. It is important that I believe that there are no 'honest' } \\
\text { mistakes - there is always an ulterior motive. (disagree) }\end{array}$} \\
\hline \multicolumn{2}{|l|}{$\begin{array}{l}\text { 37. I disliked playing on a team sport when I was in high } \\
\text { school. (disagree) }\end{array}$} \\
\hline \multicolumn{2}{|l|}{$\begin{array}{l}\text { 45. I value cooperation over competition when working as a } \\
\text { leader of a team. (agree) }\end{array}$} \\
\hline Focus & 0.744 \\
\hline \multicolumn{2}{|l|}{$\begin{array}{l}\text { 1. I stick to a task until it is complete when working on a } \\
\text { challenging project. (agree) }\end{array}$} \\
\hline \multicolumn{2}{|l|}{$\begin{array}{l}\text { 10. I concentrate hard on a task until it is done when } \\
\text { working on a challenging project. (agree) }\end{array}$} \\
\hline \multicolumn{2}{|l|}{$\begin{array}{l}\text { 15. I look for hidden meanings in things when working on a } \\
\text { challenging project. (disagree) }\end{array}$} \\
\hline \multicolumn{2}{|l|}{$\begin{array}{l}\text { 21. I try to understand myself when working on a } \\
\text { challenging project. (agree) }\end{array}$} \\
\hline \multicolumn{2}{|l|}{$\begin{array}{l}\text { 27. I try to examine myself objectively when working on a } \\
\text { challenging project. (agree) }\end{array}$} \\
\hline \multicolumn{2}{|l|}{$\begin{array}{l}\text { 39. I spend time reflecting on employee's unprofessional } \\
\text { behavior when working on a challenging project. (disagree) }\end{array}$} \\
\hline \multicolumn{2}{|l|}{$\begin{array}{l}\text { 46. I rarely look for a deeper meaning in things when } \\
\text { working on a challenging project. (disagree) }\end{array}$} \\
\hline Trustworthiness & 0.744 \\
\hline \multicolumn{2}{|l|}{$\begin{array}{l}\text { 2. It is important that I keep my promises on a business } \\
\text { commitment. (agree) }\end{array}$} \\
\hline \multicolumn{2}{|l|}{$\begin{array}{l}\text { 7. I believe that employees seldom tell you the whole truth. } \\
\text { (disagree) }\end{array}$} \\
\hline \multicolumn{2}{|l|}{ 11. It is important that I am honest. (agree) } \\
\hline \multicolumn{2}{|l|}{$\begin{array}{l}\text { 16. It is important that I am trustworthy in my business } \\
\text { relationships. (agree) }\end{array}$} \\
\hline \multicolumn{2}{|l|}{ 23. It is important that I trust what employees say. (agree) } \\
\hline \multicolumn{2}{|l|}{$\begin{array}{l}\text { 28. It is important that I trust business competitors. } \\
\text { (disagree) }\end{array}$} \\
\hline \multicolumn{2}{|l|}{ 33. It is important that I believe in human goodness. (agree) } \\
\hline \multicolumn{2}{|l|}{$\begin{array}{l}\text { 38. I find it hard to forgive employee's unprofessional } \\
\text { behavior. (disagree) }\end{array}$} \\
\hline \multicolumn{2}{|l|}{$\begin{array}{l}\text { 41. It is important that I distrust employees in subordinate } \\
\text { positions. (disagree) }\end{array}$} \\
\hline \multicolumn{2}{|l|}{$\begin{array}{l}\text { 47. It is important that I suspect hidden motives in business } \\
\text { competitors. (agree) }\end{array}$} \\
\hline Ethicalness & 0.798 \\
\hline \multicolumn{2}{|l|}{$\begin{array}{l}\text { 3. It is important that I follow the spirit of the rule of an } \\
\text { organization. (agree) }\end{array}$} \\
\hline \multicolumn{2}{|l|}{$\begin{array}{l}\text { 17. It is important that I do the "right thing" even if it causes } \\
\text { problems in the business. (disagree) }\end{array}$} \\
\hline $\begin{array}{l}\text { 24. It is important that I believe that honesty is the basis for } \\
\text { trust by the executive leadership. (agree) }\end{array}$ & \\
\hline
\end{tabular}

\begin{tabular}{|c|c|}
\hline $\begin{array}{l}\text { 29. It is important that I believe that employees are basically } \\
\text { honest and good. (disagree) }\end{array}$ & \\
\hline $\begin{array}{l}\text { 42. It is important that I try to cheat business competitors in } \\
\text { an external business relationship. (disagree) }\end{array}$ & \\
\hline 48. It is important that I try to always tell the truth. (agree) & \\
\hline Leadership & 0.771 \\
\hline $\begin{array}{l}\text { 4. I lead and direct team members when working as a leader } \\
\text { of an executive team. (agree) }\end{array}$ & \\
\hline $\begin{array}{l}\text { 8. Participating in an individual sport in high school is } \\
\text { beneficial to experience for leadership development. (agree) }\end{array}$ & \\
\hline $\begin{array}{l}\text { 12. I motivate and inspire team members when working as a } \\
\text { leader of a team. (agree) }\end{array}$ & \\
\hline $\begin{array}{l}\text { 25. I am the first to act when working as a leader of a team. } \\
\text { (disagree) }\end{array}$ & \\
\hline $\begin{array}{l}\text { 30. I am never at a loss for words when working as a leader } \\
\text { of a team. (disagree) }\end{array}$ & \\
\hline $\begin{array}{l}\text { 35. Low youth sports participation need the training to } \\
\text { develop the effective leadership traits required for future } \\
\text { management. (agree) }\end{array}$ & \\
\hline $\begin{array}{l}\text { 43. I have difficulty expressing my feelings when working } \\
\text { as a leader of a team. (disagree) }\end{array}$ & \\
\hline $\begin{array}{l}\text { 49. I wait for employees to lead the way when working as a } \\
\text { leader of a team. (disagree) }\end{array}$ & \\
\hline Decision Making & 0.882 \\
\hline $\begin{array}{l}\text { 5. I take a long time to think before making big decisions } \\
\text { when working on a challenging project. (disagree) }\end{array}$ & \\
\hline $\begin{array}{l}\text { 9. I make decisions based on facts, not feelings when } \\
\text { working on a challenging project. (disagree) }\end{array}$ & \\
\hline $\begin{array}{l}\text { 13. I think about implications before making decisions when } \\
\text { working on a challenging project. (agree) }\end{array}$ & \\
\hline $\begin{array}{l}\text { 19. I break down tasks into manageable parts when working } \\
\text { on a challenging project. (agree) }\end{array}$ & \\
\hline $\begin{array}{l}\text { 22. I listen to my feelings when making important decisions } \\
\text { when working on a challenging project. (disagree) }\end{array}$ & \\
\hline $\begin{array}{l}\text { 26. I believe important decisions should be based on logical } \\
\text { reasoning when working on a challenging project. (agree) }\end{array}$ & \\
\hline $\begin{array}{l}\text { 31. I plan and prioritize a course of action when working on } \\
\text { a challenging project. (agree) }\end{array}$ & \\
\hline $\begin{array}{l}\text { 36. I am easily overpowered when decisions need to be } \\
\text { made when working on a challenging project. (disagree) }\end{array}$ & \\
\hline $\begin{array}{l}\text { 40. I listen to my brain rather than my emotions when } \\
\text { working on a challenging project. (disagree) }\end{array}$ & \\
\hline $\begin{array}{l}\text { 44. I believe that both feelings and thinking are important in } \\
\text { making decisions and solving problems when working on a } \\
\text { challenging project. (agree) }\end{array}$ & \\
\hline $\begin{array}{l}\text { 50. I believe that important decisions should be based on } \\
\text { logical reasoning when working on a challenging project. } \\
\text { (agree) }\end{array}$ & \\
\hline
\end{tabular}

Note. a Based on 7-point scales with $1=$ strongly disagree to $7=$ strongly agree $(\mathrm{N}=325)$. b Scale items pulled from the International Personality Item Pool: A Scientific Collaboratory for the Development of Advanced Measures of Personality Traits and Other Differences.

\section{Analysis}

The analysis encompassed the order of the mean scores but not the actual value of the mean and standard deviation. The highest agreement in the items for collaboration, focus, trustworthiness, ethicalness, leadership, and decision making were Items 14, 10, 11, 24, 12, and 13, respectively (see Tables 4). The lowest levels of agreement for collaboration, focus, trustworthiness, ethicalness, leadership, and decision making were for Items 18, 39, 41, 17, 49, and 22 (see Tables 4). The dependent variable that had the highest levels of agreement for decision-making was Item 13, "I think about implications 
before making decisions when working on a challenging project." The lowest level of agreement was for Item 22, "I listen to my feelings when making important decisions when working on a challenging project."

When comparing paired data in the assessment depends on whether a measure of consistency between defined ratings of a set of objects calculates these correlations. This serves as an agreement in the ranked score in the mean and the standard deviation. Consequently, whether there is an absolute agreement is not dependent on the actual values to which the scores are attached. The purpose is to use both the order of scores and the relative values in any consideration of the relationship. This can be done for one or many measures; the dependency on data within the same context also helps measure the multilevel linear model (Field, 2013). Moreover, there was a comparison among the individual items between age and gender from the highest levels of agreement to the lowest level of agreement and listed the items in each category for collaboration, focus, trustworthiness, ethicalness, leadership, and decision-making. However, none of the items significantly related to the respondents' age category or gender.

The study did show support for the null hypothesis $H_{0}$. There is no significant relationship between decision making for executive leadership and athletic development personality factors. Subsequently, the items listed in each category of the same tables for collaboration, focus, trustworthiness, ethicalness, and leadership with the decision-making scale, age category, and gender do not support the alternative hypothesis $H_{a}$. At least one significant athletic development personality factor is related to decision-making at the executive leadership level. The dependent variable had the highest levels of agreement for decision-making for Item 31 and Item 26, but none of the decision-making items significantly related to either the respondents' age category or their gender (see Table 5). The decision-making scale included all personality factors, and there was a significant positive correlation, but none of the personality factors significantly related to the respondent's age category or gender. The data indicated support for the null hypothesis $H_{0}$ concerning the respondents' age category and their gender.

The difference between this study and Gaddis and Foster's (2015) study is that Gaddis and Foster studied successful executives versus unsuccessful executives in three U.S.-based organizations and looked at other problems when learning from an encounter, perceptivity, and making intuitive decisions that concern failures. This current study included directors, managers, and decision makers in the United States, United Kingdom, South Africa, India, and Singapore, of which 4 of the 5 are all English speaking countries. I used the maximum variation sampling of Survey Monkey's global audience decision makers to target five global regions to evaluate the performance-based model based on the assumptions and calculate the prediction errors (van Hoeven et al., 2015).
As stated above, nonparametric Spearman's rho correlations were used due to the strong Pearson's correlations across the athletic personality factors. The study involved running the Spearman's rho correlations between the athletic development personality factor, the scale score, Singapore, South Africa, the United Kingdom, the United States, and India. Each country was nonsignificant with collaboration, $r=$ $.566, p=.000$, but all personality factors had weak correlations (see Table 6). Church's (2016) study had similar results to this study, where there is a strong positive correlation between the personality factors in collaboration and decision making across countries, gender, and age group. In addition, the ANOVA was not significant and similar across age groups (see Tables 6, 7). Even though the findings from Gaddis and Foster's (2015) study were parallel with and beyond the five-factor model, the statistical measures indicated a negative direction of unskilled and authoritative jobs connected to the dark-side personality measures in projecting performance. There is economic well-being to a developed country's relationship to negative correlation. This development between conscientiousness reduces the struggle within reasons continuum for the athletic type of personality factors (Church, 2016).

Table 5 One-Way ANOVA Tests for the Scale Scores Based on Country

\begin{tabular}{|l|l|l|l|l|l|l|}
\hline Scale score and category & $n$ & $M$ & $S D$ & $\mathrm{H}$ & $F$ & $p$ \\
\hline Collaboration & & & & .25 & 1.99 & .10 \\
\hline 1. India & 27 & 5.80 & 0.57 & & & \\
\hline 2. Singapore & 23 & 5.44 & 0.76 & & & \\
\hline 3. South Africa & 24 & 5.48 & 0.70 & & & \\
\hline 4. United Kingdom & 25 & 5.71 & 0.71 & & & \\
\hline 5. United States & 25 & 5.85 & 0.53 & & & \\
\hline Focus & & & & .27 & 2.33 & .06 \\
\hline 1. India & 27 & 6.13 & 0.62 & & & \\
\hline 2. Singapore & 23 & 5.59 & 0.52 & & & \\
\hline 3. South Africa & 24 & 5.79 & 0.70 & & & \\
\hline 4. United Kingdom & 25 & 5.89 & 0.69 & & & \\
\hline 5. United States & 25 & 5.87 & 0.61 & & & \\
\hline Trustworthiness & & & & .25 & 2.01 & .10 \\
\hline 1. India & 27 & 5.61 & 0.67 & & & \\
\hline 2. Singapore & 23 & 5.26 & 0.61 & & & \\
\hline 3. South Africa & 24 & 5.10 & 0.66 & & & \\
\hline 4. United Kingdom & 25 & 5.39 & 0.88 & & & \\
\hline 5. United States & 25 & 5.51 & 0.69 & .24 & 1.81 & .13 \\
\hline Ethicalness & & & & & & \\
\hline 1. India & 27 & 5.94 & 0.62 & & & \\
\hline 2. Singapore & 23 & 5.72 & 0.62 & & & \\
\hline 3. South Africa & 24 & 6.11 & 0.62 & & & \\
\hline 4. United Kingdom & 25 & 6.06 & 0.66 & & & \\
\hline
\end{tabular}




\begin{tabular}{|l|l|l|l|l|l|l|}
\hline 5. United States & 25 & 6.14 & 0.56 & & & \\
\hline Leadership & & & & .28 & 2.50 & .05 \\
\hline 1. India & 27 & 6.04 & 0.64 & & & \\
\hline 2. Singapore & 23 & 5.50 & 0.60 & & & \\
\hline 3. South Africa & 24 & 5.69 & 0.70 & & & \\
\hline 4. United Kingdom & 25 & 5.54 & 0.82 & & & \\
\hline 5. United States & 25 & 5.74 & 0.64 & & & \\
\hline Decision Making & & & & .25 & 1.96 & .11 \\
\hline 1. India & 27 & 6.11 & 0.60 & & & \\
\hline 2. Singapore & 23 & 5.65 & 0.53 & & & \\
\hline 3. South Africa & 24 & 5.90 & 0.49 & & & \\
\hline 4. United Kingdom & 25 & 5.94 & 0.73 & & & \\
\hline 5. United States & 25 & 5.93 & 0.54 & & & \\
\hline
\end{tabular}

Note. $\mathrm{N}=124$.

Fransen et al. (2015) discussed the display of the highest correlation to the second largest overlap in a comparison of coaching leadership among educational and noneducational athletic authority structures. According to Van der Cruyssen et al. (2015), examining behavioral descriptions in the social categories affects the characteristics. The process of thinking as a link to the relationship will have meaning within the social group. A social category influences the formulation process in these arguments in recruiting and supports the predictions in knowledge, as opposed to the influence of the individual. The behavior categories will give an abundance of resources on the personality trait in the interpretation of behaviors, which has a narrow view due to the construct of the survey answers in the correlation between the personality factors and decision-making.

Survey Monkey's global audience and panel encompassed profiled population groups centered on participants' professional position as director, manager, or decision maker in executive leadership. Survey Monkey maintains a profile of company size, occupation status, age, education level, and the Field of expertise for each participant's country. Although the rest of the studies followed a similar direction, there was no connection to the dark-side personality continuum regarding nonsignificant differences between the relationship of the athletic development personality factors and decision-making outcomes. The U.S. decision-making score was the lowest for the ethical factor at $.43, p<.05$ (see Table 6). These results were dependent on the organizational answers from the directors, managers, or management decision makers' responses to the questions asked in the survey.

Findings in the behavior literature were similar to the findings on the agreement between the individual, countries, age, and gender. Corporate social sustainability is a process in decision making patterns to show the construct is the absence of the impediment for the administrative ramification in approaching total responsibility (Naseer et al., 2016; Putrevu et al., 2012). In support of the other five-factor models, researchers domestically and abroad (United States, Canada, and Europe) have encountered similar results in predicting job performance, according to Gaddis and Foster (2015). These dimensions supported the core idea of conscientiousness and emotional stability using negative measurement of personality measures not previously conducted to predict leader performance (Gaddis \& Foster, 2015). Compared with the Euro-American findings, the researchers have demonstrated that predicting performance in conscientiousness and extraversion in East Asian cultures is essential. This is based on interpersonal relationships in creating career success in Asia.

Table 6 Spearman Correlations Between Decision Making Score and Personality Factors for Selected Subgroups

\begin{tabular}{|l|c|c|c|c|c|c|}
\hline $\begin{array}{l}\text { Perso } \\
\text { nality } \\
\text { correl } \\
\text { ation } \\
\text { factor }\end{array}$ & $\begin{array}{l}\text { Entire } \\
\text { sample }\end{array}$ & India & $\begin{array}{l}\text { Singapor } \\
\mathrm{e}\end{array}$ & $\begin{array}{l}\text { South } \\
\text { Africa }\end{array}$ & $\begin{array}{l}\text { United } \\
\text { Kingdo } \\
\mathrm{m}\end{array}$ & $\begin{array}{l}\text { United } \\
\text { States }\end{array}$ \\
\hline $\begin{array}{l}\text { Colla } \\
\text { borati } \\
\text { on }\end{array}$ & $.57 * * * *$ & $.80 * * * *$ & $.51 * *$ & .32 & $.66 * * * *$ & $.49 * *$ \\
\hline Focus & $.75 * * * *$ & $.80 * * * *$ & $.73 * * * *$ & $.62 * * * *$ & $.84 * * * *$ & $.65 * * * *$ \\
\hline $\begin{array}{l}\text { Trust } \\
\text { worthi } \\
\text { ness }\end{array}$ & $.53 * * * *$ & $.61 * * * *$ & $.58 * * *$ & $.51 * *$ & $.53 * *$ & $.48 *$ \\
\hline $\begin{array}{l}\text { Ethica } \\
\text { lness }\end{array}$ & $.61 * * * *$ & $.72 * * * *$ & $.72 * * * *$ & $.49 *$ & $.76 * * * *$ & $.43 *$ \\
\hline $\begin{array}{l}\text { Leade } \\
\text { rship }\end{array}$ & $.66 * * * *$ & $.77 * * * *$ & $.64 * * * *$ & .32 & $.63 * * * *$ & $.74 * * * *$ \\
\hline
\end{tabular}

a Subgroups: $1=$ entire sample $(N=124) ; 2=$ India only $(n=27) ; 3=$ Singapore only $(n=23) ; 4=$ South Africa only $(n=24) ; 5=$ United Kingdom only $(n=25)$; and $6=$ United States only $(n=25)$.

$* p<.05 . * * p<.01 . * * * p<.005 . * * * * p<.001$.

Researchers have indicated that conscientiousness correlations are reasonably accurate in response styles, reference group effects, national stereotypes, and measurement invariances. Studies on political patterns, wealth, and crime were examples that aligned with the geographic patterns of the Big Five, according to Church (2016). The questions, then, are about the validity of crosscultural trait comparisons and the counterintuitive correlations involving conscientiousness. The use of country-level behavioral indicators affecting conscientiousness in the human development of competitiveness in a multinational sample of working adults indicated that conscientiousness and economic development produce unexpected negative correlations, as reflected in the oversampling of college students.

In contrast to agreeableness and conscientiousness being the highest among older adults, highest in adults, and lowest in adolescents, stereotypes are consistently different in measured traits between gender and age (Church, 2016). In the decision-making scale, women had higher levels of agreement with Item 12, "I motivate and inspire team members when working as a leader of a team" and lower 
levels of agreement with Item 25, "I am the first to act when working as a leader of a team" (see Table 4). Agreeableness, conscientiousness, and openness to experience for gender and age stereotypes are lower in men with traits and converge across cultures.

There is an agreement in theory regarding the relationship between the predictor variable and the response variable. In the current study, the scale was verified reliability using the scale developed by Young et al. (2013) to compare the reliability. Fransen et al.'s (2015) findings showed different perceptions in global leadership regarding the various leadership roles and why good leadership has differences that only moderate correlational emergence in the corroborated specific authority roles that compel definite authoritative excellence. The scale categorized a network of items, including the roles of the task and the motivational, social, and extrinsic authority in having a continuum associated with factors as a predictive or dependent variable. These variable classifications aligned with the alternative hypotheses as a positive correlation between the different athletic development factors.

\section{VI.THEORETICAL FRAMEWORK EXPANSION}

The significance of leadership theories for advancing members of society as leaders is to create theoretical frameworks to understand transformational, transactional, member exchange, servant leadership, and situational leadership. Researchers have created a significant amount of literature to align with the role of the executive coach in organizational leadership settings. This linkage of the behavior continuum of leadership styles can be the motivation form toward organizational performance.

There are forms of leadership that are less dependent on direction from coaches, but there are similarities to leadership in organizations. Sports psychology research refers to social and communal relationships with their teammates and coaches as individual levels of measurement. Researchers are finding many gaps in the research based on their assessment of teamlevel constructs in leadership literature. The interpretative factors used in social representations of educational success or failure for children provide the constraint and meaning of practices and norms, either right or wrong rather than true or false (Tateo \& Iannaccone, 2012). Culture is a common element in connecting individuals and civilizations as a personality continuum linking innovations between generations within a person's negotiated space.

However, management has conflicting interpretations concerning which authoritative qualities align with the intrinsic and external relationships. I believe the wellestablished five-factor model of personality traits survey instrument may have been too complex for this study. The selected scales and measurement of variables were constructs from the motorsports context based on success factors identified by Young et al. (2013). Organizational leaders can view the effect of an executive leader's or a C-level executive's decision-making ability on the economic, social, cultural, and environmental sustainability of an organization. These organizational changes may lead to failure due to the poor decisions of the executive leadership.

The Big Five factors advanced through an exploration into Cattell's 16 personality factors theory are warmth, reasoning, emotional, stability, dominance, liveliness, ruleconsciousness, social boldness, sensitivity, vigilance, abstractedness, privateness, apprehension, openness to change, self-reliance, perfectionism, and tension (Fehringer, n.d.). Researchers have found it challenging to replicate Cattell's factors in other studies. For instance, Cattell and other researchers did not gain validity well into the late $20^{\text {th }}$ century, but advances in technology and further investigation have validated Cattell's model. The following Big Five factors are now the dominant paradigm in personality research: openness, conscientiousness, extraversion, agreeableness, and neuroticism (Bouchard, 2016; Fehringer, n.d.). Although, the well-established five-factor model of personality traits was not used as part of the survey instrument.

Social scientists have not found group consensus in consistently measuring such characteristics and behaviors. This characteristic and behavior personality factor influences the leadership style in developing a socially conscious leader in combatting the competitive landscape in the global business environment. Social representation theory belongs to various social groups has balancing attributes toward the actions of the individual and at the same reference of time within the group. Therefore, findings on leaders' effectiveness were contradictory in past research when exploring constructive and adverse relationships between authentic leadership and followers' optimism and perceptions. Even though random sampling has a high regard in the process of sampling strategies about not having biased tendencies, there is a chance to misinterpret the reliability of its projections (van Hoeven et al., 2015). Furthermore, when using purposive sampling, researchers might find themselves in a conflict when selecting a sample person or group if there is an issue between randomization and logical intentions.

\section{LIMITATIONS OF THE STUDY}

There were constraints in choosing athletic development personality factors as the predictive variables while examining the survey questions to facilitate responses with Survey Monkey's Audience global panel. Regardless of whether a sample is anonymous, finding a sample of top management and $\mathrm{C}$-suite executives had boundaries in obtaining specific references to confirm these leaders' roles. The use of the global panel in Survey Monkey's Audience platform to target a particular population found the professional positions held were directors, managers, and decision makers in executive leadership as the primary profile factor as part of the profile classification.

The participants identified the size of their company, whether they worked full time, and their Field of expertise 
concerning their role as a director, manager, or decision maker in executive leadership. However, these identifiers were not part of the 50-question survey, which would have meant adding another type of question other than the 7-point Likerttype scale used in this study. Nevertheless, due to the financial constraints in cost to a researcher, a quantitative method may negate the opportunity to identify a sample, enhance and improve future studies. There is a debate on whether a selfrater survey obtains honest answers. Consequently, another limitation is the resources needed to target a population of employees to evaluate top management and decision makers on whether the employees can identify defects in the antisocial behavior of their managers' personality, characteristics, or traits.

Köksal et al. (2014) mentioned that discrepancies originating from data collectors, researchers, investigators, or whoever is collecting the data could lead to differences in the values of reliability and validity. These issues have a negative effect on the accuracy of inferences based on measurements and self-reporting surveys. Distortion or bias may exist but suggested patterns of response in the findings among executive leadership in large, midsize, and small companies may not apply toward a broader population.

\section{RECOMMENDATIONS}

The bases for the recommendations for further research are the strengths and limitations of this current study, as well as the exhaustive literature. In addition, the use of SPSS software may be suitable for analyzing the relationship between the variables in this correlational study. However, multiple instruments parallel the study's construct, as discussed in similar research models presented in the literature review. An appropriate instrument related to the athletic development personality factors from Young et al.'s (2013) study is the Leadership Scale for Sport. Chelladurai (1984) created a 40-item instrument that included five types of leadership behavior. The first classification was training and instruction to the relationship for a performance improvement program aimed at behavior. The second decision was to work collectively. The third was the authority personally given by the leader, the fourth was considering others' well-being, and the fifth was the positive reinforcement given as a reward to the team members. This instrument provides a valid and reliable scale.

The MLQ Form 5X-Short is instrument researchers use widely for measuring leadership styles. Researchers use the OCAI to start a dialogue about where an organization is and what it would like to become. The competing values framework is a predictor of quality leadership and organizational effectiveness for the approved implementation of the employee, patient satisfaction, and team functioning, among other outcomes. Leadership types range from passive leaders to leaders who reward followers to leaders who transform followers into management positions; the MLQ measures the leadership development process.
Transformational leaders identified characteristic measures from those they work with and from the leader's point of view. Leadership programs track changes in leadership through retesting and providing the MLQ training program.

The maintenance of a successful interpersonal relationship shows inspiration by teaching for a future vision. However, researchers lack the knowledge in various areas that indicates authority is a dynamic exchange of the leaderfollower relationship. A comprehensive strategy recognizes future failures through lessons learned from others, as business failures are frequent (Amankwah-Amoah, 2014). The current political nature is between leaders and followers personality variables and cultures. This aid to the leadership literature is a negative contribution that is problematic for leaders (Naseer et al., 2016). The exploration of adverse conditions of the cloudy side of leadership for top executives and leaders is an ongoing issue for organizations (Naseer et al., 2016). The differences were examined in each country and between the countries as a deciding factor for future research in the various cultural perspectives on the bright and dark side of leadership.

Table 7 Frequency Counts for Selected Demographic Variables

\begin{tabular}{|l|c|c|}
\hline Variable and category & $N$ & $\%$ \\
\hline Country & & \\
\hline India & 27 & 21.8 \\
\hline Singapore & 23 & 18.5 \\
\hline South Africa & 24 & 19.4 \\
\hline United Kingdom $^{\prime}$ & 25 & 20.2 \\
\hline United States $^{\text {a }}$ & 25 & 20.2 \\
\hline Age category & & \\
\hline $18-29$ & 14 & 11.3 \\
\hline $30-44$ & 80 & 64.5 \\
\hline $45-59$ & 24 & 19.4 \\
\hline $60+$ & 6 & 4.8 \\
\hline Gender & & 32.3 \\
\hline Female & 40 & 67.7 \\
\hline Male & 84 & \\
\hline
\end{tabular}

Note. $\mathrm{N}=124 .{ }^{\mathrm{a}} \mathrm{Mdn}=37$ years old.

A particular characteristic may have thousands of common genetic variants that appear in each trait as a minuscule effect. According to Church (2016), researchers have found it difficult to identify genetic variants of personality trait scores that are significant and reliable. At the same time, the investigation on how culture genes coevolve is based on selective migration in cultural neuroscience, the effect on the neural architecture, cultural dimensions, and personality factors. Thus, future studies may be necessary on trait structure in less developed or preliterate societies to gain consistency, validity, and strong correlations among financial and social factors. 
Future researchers should address the following questions:

1. How does decision making in a cultural exchange between communications processes such as social media, networking, and the Internet influence executive leadership?

2. How does the growth of the social sciences affect the development of management decision making and the psychological relevance to personality factors by the scholarship of executives?

3. How does executive leadership relate cultural perspective and change management methods in decision-making?

A decision approach involves measuring competence while accessing individuals' management of the decision process, both pre- and post decision, such as indecision or regret. The study did not include any measures of decision competence other than the construct developed from Young et al. (2013) study and the IPIP.

\section{IMPLICATIONS}

Opportunities are found to search for gaps that can be as simple as redoing a study using different countries, a particular industry, a specific methodology, or many wellestablished surveys and questionnaire instruments. In addition, cognitive skill transfer may play a role in the transfer of executive function skills. However, learning from the classroom to the workplace setting has faced difficulties (Holten et al., 2015; Jacobson \& Matthaeus, 2014). Thus, this transference of skills focuses on linking personality with leadership, despite the lack of leadership theory and research contributions. As a result, the combined relationship of the individual, moral issues, and organizational characteristics presents research gaps. According to By, Armenakis, and Burnes (2015), not much has changed since the 2008 financial crisis. The established practices of organizations are still unethical. A few unscrupulous decision makers are still making bad decisions, and the core of the team is absorbing these practices at all levels of an organization. New laws and restructured codes will not solve these problems, but replacing unethical cultures with ethical cultures will help.

Researchers can formulate a qualitative research plan by addressing the size and diversity of the sample and acknowledging that qualitative studies include probabilitysampling designs that drive a predetermined purpose (Griffith, 2013). In contrast, quantitative studies use probabilitysampling designs, with their most essential features derived from randomness (Griffith, 2013). In addition, researchers may explore processes, activities, and events in a narrative, ethnography, phenomenology, case study, or grounded theory approach. Therefore, researchers can target the population and sample of executives from small, midsize, or large corporations to create a sample that represents a particular community; divide the executive leadership into structured groups configured by the size of the company or the location of the country, and randomly choose one group to represent each of the groups for interviews.

A research project strategy can have options divided into three phases; narrative, phenomenology, ontology, grounded theory, and case study approach; qualitative methods present some interesting perspectives on the available options. For example, researchers use both interviews and observations to achieve triangulation within an attained inquiry strategy by mixing different types of purposeful samples (Patton, 2002), which allows researchers to produce additional scalable studies in the evolution from one approach to the following approach or a combination of all three strategies. Subsequently, the connection between the data and the colorcoded phrases shows a connection to establishing the themes and subthemes that indicate an efficient way to make word associations when reporting the differences in hand coding compared to NVivo or SPSS software.

Failures are common in organizations' current decisionmaking direction, but through lessons learned, an acknowledgment that is persistent in overcoming leadership business failures (Amankwah-Amoah, 2014). Although, there is a need for organizational leaders to identify, correct, and transfer the athletic development personality factors (independent variable) as part of the lessons learned in the correlation of variables for the business and to understand leadership failures across countries. The critical point is that quantitative research is a significant motivator of ethical behavior when testing specific hypotheses in moral identification and is suitable when deviant behavior serves as voluntary behavior that occurs when motivated groups are in violation or when people lack the motivation to conform to organizational norms and standards (Joosten et al., 2014). Consequently, researchers using longitudinal designs have reached similar findings regarding better cognitive functions in association with long-term exercise training and improved fitness levels, as well as a delay in age-related cognitive decline.

In examining leaders and leadership development in the content, processes, longitudinal nature, and evaluation of issues, researchers find it is the process rather than replacing leadership development. According to Day et al. (2013), the historical evolution of leadership includes an in-depth analysis to build in leadership development with a detailed summary. The underlying leadership patterns in the various approaches enable other researchers to understand the competencies for examining cognitive and metacognitive skills that surface at the core of leadership potential.

On the one hand, researchers can measure personality in many ways using multiple-source ratings for determining leaders' current needs in development (Day et al., 2013). However, on the other hand, researchers acknowledge that the evolution and growth of leadership begin at a young age, as determined by parental modeling that affects the evolutionary process and the application of skills in wisdom, intelligence, 
and creativity assembled by factors such as personality and exchanges with others. Consequently, the holistic approach shapes the development process through different theories, including constructive development, transformational, shared, and authentic leadership.

\section{SOCIAL CHANGE IMPLICATIONS}

Gaps in the literature review revealed opportunities in the research of personality factor relationships that affect top management's impact on employees and the decisions made in organizational activities. On the one hand, knowledge of human biological learning processes leads to solutions based on the transfer of learning to strengthen future leadership development programs (Holten et al., 2015). On the other hand, the complex need to improve physical activity through causal pathways between environmental factors and human behaviors compounds the understanding of these factors becomes a benchmark in creating positive social change for further research. Researchers are continuously searching for answers by asking how executive leadership affects labor relations and what problems executive leaders have in promoting personal motives.

Conversely, researchers find it challenging to identify youth personality traits due to a lack of longitudinal studies. Therefore, transferring athletic development personality factors may be a problem with individuals and organizations' relationship to the social exchange, social representation, and leadership theories. In addition, using sports ideology has other ramifications regarding the relationship to sports development types of organizations, sports for social change, engagement through sports, and other terms and language that need clarification (Tannenwald, 2013). For this reason, approaches involving groups and large collectives that happen over time increase the change patterns within and between the person from a multilevel and longitudinal perspective.

\section{POLICY RECOMMENDATIONS}

The findings in this study indicated that participants in Singapore, South Africa, the United Kingdom, the United States, and India profiled a similarity in the athletic development personality factors and decision making with the nonsignificant coefficients outcomes. Despite this, the policy implications of corporate social sustainability and responsibility toward decision-making may lead to a lack of understanding in the hindrance of behavior (Naseer et al., 2016; Putrevu et al., 2012). The attempt to understand social practices can involve using Moscovici's social representations theory to provide a broader social and historical context to the analysis of organizational practices (Naseer et al., 2016). The corporate policies will have a direct relationship to the decision made by decision makers across various behavior patterns.

\section{PRACTITIONER RECOMMENDATIONS}

Organizational leadership is the primary concern and principle interest of scholars in the thinking processes for leadership development. Strong causal interpretations are necessary due to the lack of evidence supporting longitudinal research of clearly defined variables (Brittin et al., 2015). According to some researchers, focusing on the bright side of personality focuses on leveraging relationships with leadership behavior (Gaddis \& Foster, 2015). A need exists for leadership training and development that provide managers with meta-skills to communicate, translate organizational visions, and engage employees toward organizational goal attainment (Holten et al., 2015). These factors will enable a process to evolve in pinpointing personality factors that need to be addressed by human resource departments.

\section{CONCLUSION}

The context of personality has an evolutionary perspective in identifying the problems of human personality dimensions in the age of globalization, enabling people of all cultures to reflect on recurrent themes to facilitate strategic goals in detecting the differences in developmental mechanisms. These themes in Personality traits in individualism-collectivism link the genetic variants from studies on molecular genetics to the tightness-looseness of the cultural dimensions. Correspondingly, the study intended to see if a significant correlation existed between athletic personality factors and decision-making. The study involved assessing how well the personality of the executive leadership decisions makers reaches satisfactory decision outcomes. Many decision-making measures relate to cognitive-style and decision-style measures.

The result in this study was not consistent with Gaddis and Foster's (2015) study, as they found that individual variations result from flawed leadership behavior that coexists between the continuums of characteristics. In contrast, the findings in this study were from theme-based interviews rather than from this survey-based correlational study. Comparatively, the researcher asked various questions regarding each of the athletic development personality factors; thus, a different statistical measure would have occurred from the different self-rated responses. Therefore, due to the various self-rated responses, it was necessary to decipher these statistical measures into a quantitative methodology rather than to use interviews for a qualitative study.

More studies are necessary to investigate situational factors for the variability in trait-related behaviors. Researchers can better integrate character and social cognitive perspectives across cultures in the situational exchange with the individual (Church, 2016). Subsequently, new integrative frameworks may address biological, ecological, and cultural contexts of personality (Church, 2016). Also, offering leadership scholars a vehicle to conceptualize their experience in the relevant skills, knowledge, and practice acquired while holding various jobs may interest researchers studying the role of experience in leader development (Day et al., 2013). Therefore, the research implications regarding understanding 
personality may enhance people's accessibility through e-mail and the Internet, which improves; this form of social media provides numerous advantages for future researchers.

\section{ACKNOWLEDGEMENTS}

I am thankful for my journey with my parents, who ingrained in me the value of family, education, and that a person can achieve their dreams with hard work. To my amazing daughter and son, Jennifer, and Aaron, whose support, words of encouragement, and prayers helped me stay focused. Lastly, to my grandchildren, Leah, Alex, and Aaron, that they grow up to understand the importance of leadership and the value of quality education. I am also grateful for the guidance, direction, and mentorship from Dr. McCollum, Dr. James Fogal, and Dr. Jain.

\section{REFERENCES}

[1] Amankwah-Amoah, J. (2014). A unified framework of explanations for strategic persistence in the wake of others' failures. Journal of Strategy and Management, 7, 422-444. doi:10.1108/JSMA-01-2014-0009

[2] Antes, A. L., Thiel, C. E., Martin, L. E., Stenmark, C. K., Connelly, S., Devenport, L. D., \& Mumford, M. D. (2012). Applying cases to solve ethical problems: The significance of positive and process-oriented reflection. Ethics \& Behavior, 22, 113-130. doi:10.1080/10508422.2012.655646

[3] Bouchard, T. J. (2016). Experience producing drive theory: Personality "writ large." Personality and Individual Differences, 90, 302-314. doi:10.1016/j.paid.2015.11.007

[4] Brittin, J., Sorensen, D., Trowbridge, M., Lee, K. K., Breithecker, D., Frerichs, L., \& Huang, T. (2015). Physical activity design guidelines for school architecture. PLoS One, 10. doi:10.1371/journal.pone.0132597

[5] By, R. T., Armenakis, A. A., \& Burnes, B. (2015). Organizational change: A focus on ethical cultures and mindfulness. Journal of Change Management, 15, 1-7. doi:10.1080/14697017.2015.1009720

[6] Cavallera, G.M., Passerini, A., \& Pepe A. (2013). Personality traits and the role of gender in swimmers at the leisure level. Social Behavior and Personality, 41, 693-703. doi:10.2224/sbp.2013.41.4.693

[7] Chelladurai, P. (1984). Discrepancy between preferences and perceptions of leadership behavior and satisfaction of athletes in varying sports. Journal of Sport Psychology, 6, 27-41. doi.org/10.1123/jsp.6.1.27

[8] Chien, Y. (2014). Key factors' weight evaluation of a manager's leadership skill and personality traits upon job performance as exemplified with Taiwanese listed IC design houses. Journal of Global Business Management, 10, 38-51. http://www.jgbm.org/page/5\%20Yung-Chieh\%20Chien.pdf

[9] Church, A. (2016). Personality traits across cultures. Current Opinion in Psychology, 8, 22-30. doi: 10.1016/j.copsyc.2015.09.014

[10] Cohen, J. (1988). Statistical power analysis for the behavioral sciences (2nd ed.). Mahwah, NJ: Lawrence Erlbaum. doi.org/10.4324/9780203771587

[11] Day, D. V., Fleenor, J. W., Atwater, L. E., Sturm, R. E., \& McKee, R. A. (2013). Advances in leader and leadership development: A review of 25 years of research and theory. Leadership Quarterly. 25, 63-82 doi.org/10.1016/j.leaqua.2013.11.004

[12] Delaney Peter F., Goldman Jacqueline A., King, Jake S., \& Nelson-Gray Rosemery O. (2015). Mental toughness, reinforcement sensitivity theory, and the five-factor model: Personality and directed forgetting. Personality and Individual Differences, 83, 180-184. doi: 10.1016/j.paid.2015.04.020
[13] Endrijaitis, R., \& Alonderis, A. (2015). Towards sustainable security: Complex dynamic systems and leadership. Journal of Security \& Sustainability Issues, 4, 279-293. doi:10.9770/jssi.2015.4.3

[14] Evans, J. D. (1996). Straightforward statistics for the behavioral sciences. Pacific Grove, CA: Brooks/Cole.

[15] Farh, C. C., Seo, M., \& Tesluk, P. E. (2012). Emotional intelligence, teamwork effectiveness, and job performance: The moderating role of job context. Journal of Applied Psychology, 4, 890-900. doi:10.1037/a0027377

[16] Fehringer, H. M. (n.d.). Cattell's sixteen personality factor model. Retrieved http://www.personalityresearch.org/papers/fehringer.html

[17] Field, A. (2013). Discovering statistics using IBM SPSS statistics 4th ed.). Thousand Oaks, CA: Sage.

[18] Fransen, K., Van Puyenbroeck, S., Loughead, T. M., Vanbeselaere, N., De Cuyper, B., Vande Broek, G., Boen, F. (2015). Who takes the lead? Social network analysis as a pioneering tool to investigate shared leadership within sports teams. Social Networks, 43, 28-38. doi:10.1016/j.socnet.2015.04.003

[19] Gaddis, B. H., \& Foster, J. L. (2015). Meta-analysis of dark side personality characteristics and critical work behaviors among leaders across the globe: Findings and implications for leadership development and executive coaching. Applied Psychology: An International Review, 64, 25-54. doi:10.1111/apps.12017

[20] Griffith, D. A. (2013). Establishing Qualitative Geographic Sample Size in the Presence of Spatial Autocorrelation. Annals of the Association of American Geographers, 103, 1107-1122. doi:10.1080/00045608.2013.776884

[21] Holten, A.-L., Bøllingtoft, A., \& Wilms, I. (2015). Leadership in a changing world: Developing managers through a teaching and learning the programme. Management Decision, 53, 1107-1124. doi:10.1108/MD-10-2014-0617

[22] International Personality Item Pool: A scientific collaboratory for the development of advanced measures of personality traits and other individual differences. (2016). Retrieved from http://ipip.ori.org

[23] Jacobson, J., \& Matthaeus, L. (2014). Athletics and executive functioning: How athletic participation and sport type correlate with cognitive performance. Psychology of Sport and Exercise, 15, 521-527. Retrieved from doi.org/10.1016/j.psychsport.2014.05.005

[24] Joosten, A., van Dijke, M., Van Hiel, A., \& De Cremer, D. (2014). Being "in control" may make you lose control: The role of selfregulation in unethical leadership behavior. Journal of Business Ethics, 121, 1-14. doi:10.1007/s10551-013-1686-2

[25] Köksal, M. S., Ertekin, P., \& Çolakoğlu, Ö. M. (2014). How differences among data collectors are reflected in the reliability and validity of data collected by likert-type scales? Educational Sciences: Theory \& Practice, 14, 2206-2212. doi:10.12738/estp.2014.6.2028

[26] Naseer, S., Raja, U., Syed, F., Donia, M., \& Darr, W. (2016). Perils of being close to a bad leader in a bad environment: Exploring the combined effects of despotic leadership, leader member exchange, and perceived organizational politics on behaviors. Leadership Quarterly, 27, 14-33. doi: 10.1016/j.leaqua.2015.09.005

[27] Patton, M. Q. (2002). Qualitative research and evaluation methods (3rd ed.). Thousand Oaks, CA: Sage Publications, Inc. https://doi.org/10.1177/10928102005003006.

[28] Putrevu, S., McGuire, J., Siegel, D. S., \& Smith, D. M. (2012). Corporate social responsibility, irresponsibility, and corruption: Introduction to the special section. Journal of Business Research. 65, 1618-1621. doi: 10.1016/j.jbusres.2011.10.020

[29] Ross, S., Metcalf, A., Bulger, S. M., \& Housner, L. D. (2014). Modified Delphi investigation of motor development and learning in physical education teacher education. Research Quarterly for Exercise and Sport, 85, 316-329. doi:10.1080/02701367.2014.930087 
[30] Tannenwald, D. (2013). The power to change the world? The role of sport in development. Kennedy School Review, 13, 68-72. $\mathrm{http} / / /$ harvardkennedyschoolreview.com/the-power-to-change-theworld-the-role-of-sport-in-development/

[31] Tateo, L., \& Iannaccone, A. (2012). Social representations, individual and collective mind: A study of Wundt, Cattaneo, and Moscovici. Integrative Psychological \& Behavioral Science, 46, 57-69. doi:10.1007/s12124-011-9162-y

[32] Towndrow, P. A., \& Vallance, M. (2013). Making the right decisions: Leadership in 1-to-1 computing in education. International Journal of Educational Management, 27, 260-272. doi:10.1108/09513541311306477
[33] Van der Cruyssen, L., Heleven, E., Ma, N., Vandekerckhove, M., \& Van Overwalle, F. (2015). Distinct neural correlates of social categories and personality traits. NeuroImage, 104, 336-346. doi:10.1016/j.neuroimage.2014.09.022

[34] van Hoeven, L. R., Janssen, M. P., Roes, K. B., \& Koffijberg, H. (2015). Aiming for a representative sample: Simulating random versus purposive strategies for hospital selection. BMC Medical Research Methodology, 15, 90. doi:10.1186/s12874-015-0089-8

[35] Young, J. A., Bodey, K. J., Harder, J. T., \& Peters, R. (2013). An examination of personality traits of motorsports management students. ICHPER-SD Journal of Research, 2, 33-38. Retrieved from http://ichpersd.org/index.php/journal /ichpersd-journal-ofresearch 